\title{
EMPATHY ONLINE AND MORAL DISENGAGEMENT THROUGH TECHNOLOGY AS LONGITUDINAL PREDICTORS OF CYBERBULLYING VICTIMIZATION AND PERPETRATION
}

\author{
I.Marin-Lopez, I. Zych, R. Ortega-Ruiz, C. P. Monks \& V. J. Llorent \\ Accepted for publication in Children and Youth Services Review 4/6/20
}

\begin{abstract}
Cyberbullying is a form of peer-aggression performed using electronic devices, by one or more individuals, with the intention to harm the cybervictims, who have difficulties in defending themselves. Diverse interpersonal variables such as empathy and mechanisms such as moral disengagement are involved in face-to-face and online interpersonal interactions. Many studies related empathy and moral disengagement to cyberbullying, but none have yet studied them together with online empathy and moral disengagement through technology. This study aimed to analyze the relationships among cyberbullying, online empathy, and moral disengagement through technology and to explore whether the dynamics established among those variables were stable over time. Participants were 1,033 students (age range 11-17 years old; $\mathrm{M}=13.66 ; \mathrm{SD}=1.64 ; 48.32 \%$ girls) enrolled in public and private schools in the south of Spain. A second wave of data collection included 534 participants (52.17\%; age range 12-18 years old; $\mathrm{M}=14.10 ; \mathrm{SD}=1.33 ; 49.82$ $\%$ were girls). This study used a prospective longitudinal design. The results showed that high moral disengagement through technology was related to cyberbullying, especially in the cyberbully/victim role. The role of online empathy did not seem to have such a clear relation with cyberbullying. The need for more research in this area is highlighted.
\end{abstract}

Key words: empathy online; moral disengagement through technology; cyberbullying; risk and protective factors; longitudinal predictors 
Cyberbullying is a form of peer-aggression performed using electronic devices by an individual or a group of individuals, who intentionally harm the victims who are not able to easily defend themselves (Smith et al., 2008). Cyberperpetrators repeatedly inflict harm or discomfort on others through harmful online content (Patchin \& Hinduja, 2006; Slonje \& Smith, 2008; Smith et al., 2008; Tokunaga, 2010). Menesini and colleagues (2012) stated that an imbalance of power between the perpetrator and a target is more important than the repetition. An act of cyberaggression can remain online for a long time (Slonje \& Smith, 2008; Sugarman \& Willoughby, 2013; Wolak, Mitchell, \& Finkelhor, 2007) which implies that the harmful content can be shared, replayed or even saved on an electronic device or in a cloud, making the suffering of the cybervictim continue. Other specific characteristics of cyberbullying are the possible anonymity of the cyberperpetrator, the lack of importance of physical strength (Nocentini et al., 2010), and that it can occur at any time any day or night (Kowalski, Limber, \& McCord, 2019). Although some authors have stated that one of the defining characteristics of cyberbullying is repetition (Smith et al., 2008), there is a debate around this topic (Casas, Ortega-Ruiz, \& Monks, 2020). Some authors argue that, due to the characteristics of the Internet, just one or two harmful acts could be enough to be considered cyberbullying, not considering the characteristic of repetition to be mandatory (Gámez-Guadix, Borrajo, \& Almendros, 2016; Juvonen \& Gross, 2008; Kowalski \& Limber, 2007; Vieno, Gini, \& Santinello, 2011).

Cyberbullying has become a worldwide phenomenon that has been studied in different geographic areas. Modecki, Minchin, Harbaugh, Guerra, and Runions (2014) carried out a meta-analysis of 80 international studies and found that around $15 \%$ of children were victims of cyberbullying and around $15 \%$ were cyberbullies worldwide. Many studies have looked at various factors to try to further understand cyberbullying. Zych, OrtegaRuiz and Marín-Lopez (2016) found that the prevalence of cyberbullying varied depending on the measurement strategies. Sorrentino, Baldry, Farrington and Blaya (2019) conducted a study across Europe using the same procedures and measures, thereby minimizing bias due to methodological factors and found a prevalence rate of cybervictimization ranging from $8.3 \%$ (Spain) to $46.2 \%$ (Bulgaria), and a cyberperpetration prevalence rate ranging from $7 \%$ (Spain) to $26.8 \%$ (Hungary). 
Thus, cyberbullying is a complex and serious problem for young people all over the world. The characteristics of cyberbullying itself, together with the features of online interpersonal communication, and different interpersonal variables involved in online interactions make the understanding of cyberbullying more complex. Moreover, some variables such as empathy and moral disengagement present in online interaction still need to be thoroughly studied. Most of the studies in the field are cross-sectional and do not make it possible to differentiate predictors from correlates. Thus, the current study focuses on empathy and moral disengagement online using a prospective longitudinal design.

\section{Cyberbullying and Empathy}

A key interpersonal variable present in interpersonal interactions is empathy. Empathy is defined as "understanding and sharing another's emotional state or context" (Cohen \& Strayer, 1996, p. 988). This complex construct is divided into two dimensions, cognitive and affective empathy. Cognitive empathy is the ability to understand the emotions that other people are feeling or their emotional context. Affective empathy is the ability to experience and share other peoples' emotional states and emotional contexts (Jolliffe \& Farrington, 2006).

Empathy has been found to have a positive relationship with intelligence, extraversion, agreeableness, conscientiousness, and openness (Jolliffe \& Farrington, 2006), whereas low empathy is associated with antisocial behaviors (Jolliffe \& Farrington, 2004; Zych \& Llorent, 2019). Positive relationships have also been found among moral reasoning, prosocial reasoning, and empathy. These constructs, positively interconnected, are involved in affective and cognitive processes. Thus, it seems that, in the moral development of an individual, there is a positive relationship between affective and cognitive processes (Retuerto, 2002). It is possible that something similar occurs regarding cognitive and affective empathy online and antisocial behaviors such as cyberbullying, but more research is needed to fully understand these relations.

Many studies have indicated that empathy is a predictor of cyberperpetration, finding associations between low levels of empathy and cyberperpetration (Ang, \& Goh, 2010; Brewer, \& Kerslake, 2015; Kowalski, Giumetti, Schroeder, \& Lattanner, 2014; Steffgen König, Pfetsch, \& Melzer, 2011), and high levels of empathy in cybervictims (Pettalia, Levin, \& Dickinson, 2013; Pabian, Vandebosch, Poels, Van Cleemput, \& Bastiaensens, 
2016; Doane, Pearson, \& Kelley, 2014; Kokkinos, Antoniadou, \& Markos, 2014). Schultze-Krumbholz and Scheithauer (2009) found lower levels of empathy in victims and perpetrators than those who were uninvolved, but other researchers found no significant relationship between empathy and cyberperpetration (Garaigordobil, \& MartínezValderrey, 2015; Pettalia et al., 2013), and empathy and cybervictimization (Kowalski, Giumetti, Schroeder, \& Lattanner, 2014; Renati, Berrone, \& Zanetti, 2012). Zych and colleagues (2019), in a meta-analysis regarding empathy in different cyberbullying roles, found that cyberperpetrators score low on both affective and cognitive empathy dimensions. They also found higher levels of affective empathy in cybervictims compared to non-victims. These inconsistent findings may reflect the diversity of circumstances, samples and even instruments used.

Focusing on communication through electronic devices, Carrier, Spradlin, Bunce and Rosen (2015) suggested that "online or virtual empathy" is shown through online interpersonal interactions, and they found significant positive correlations between offline empathy and virtual empathy, with online empathy levels being lower than offline empathy levels. They found that affective empathy was lower than cognitive empathy, and that cognitive empathy levels decreased more online than the levels of affective empathy. Caplan and Turner (2007) proposed that online communication could foster empathy or even increase it (e.g., people finding and establishing contact online with people who are in similar situations to them, as suggested by Van Zalk, Van Zalk, Kerr, \& Stattin, 2014). In contrast, other studies suggested that the exposure to violent content online could be a causal risk factor for lower levels of empathy, less prosocial behavior, and higher levels of aggressive conduct offline (Anderson et al., 2010). This suggests that online behaviors could foster certain offline behaviors and vice versa. It is thus relevant to keep conducting research on this topic, in order to discover whether key human behavioral characteristics such as empathy are expressed differently when interacting online. Moreover, it is crucial to discover these relations through longitudinal studies that make it possible to distinguish predictors from correlates.

\section{Moral disengagement as a predictor of cyberbullying}

Another relevant personal variable that can be found in interpersonal interactions is moral disengagement. Moral disengagement is a set of mechanisms the individuals use to excuse their immoral or harmful behavior in order to avoid setting themselves punishments 
for their breach of moral values (Bandura, 2002). This process includes four moral disengagement strategies that are compound by a total of eight mechanisms such as cognitive restructuring includes mechanisms such as euphemistic labelling, advantageous comparison, and moral justification. Minimization of one's own role includes mechanisms such as displacement/diffusion of responsibility. Ignorance or distortion of the consequences includes disregarding/distorting consequences, and blaming or dehumanization of the victim includes attribution of blame and dehumanisation (Bandura, 1990;1991; 2016).

Some studies have found that moral disengagement predicts cyberbullying perpetration (Bussey, Fitzpatrick, \& Raman, 2015; Robson \& Witenberg, 2013; Wachs, 2012), although other studies such as Perren and Gutzwiller-Helfenfinger (2012) indicated that moral disengagement was not predictive of cyberbullying. A meta-analysis carried out by Gini, Pozzoli and Hymel (2014) found a statistically significant relationship between moral disengagement and aggressive behavior including cyberbullying. Zych, GómezOrtiz, Touceda, Nasaescu and Llorent (2019) reported a relationship between high scores in parental moral disengagement induction as perceived by their children and high scores in cyberbullying perpetration mediated by high moral disengagement and low moral emotions. Renati and colleagues (2012) reported higher levels of moral disengagement in both cyberperpetrators and cybervictims than those not involved in cyberbullying.

Given that cyberspace has become a new and potent context for moral and immoral actions, it is necessary to study moral disengagement specifically applied to online interaction. Runions and Bak (2015) proposed a conceptual framework to address how certain features of cyberspace such as the lack of social and emotional cues, the effortless dissemination of communication through online social networks, and even the attention that the media pay to cyberbullying (that may provoke moral justification, euphemistic labeling, palliative comparison, diffusion and displacement of responsibility) may facilitate moral disengagement. Yadava, Sharma and Gandhi (2001) described the existence of moral disengagement in online interpersonal interactions. Recently, Paciello and colleagues (2020) made a differentiation between offline and online operationalization of moral disengagement. They demonstrated that traditional moral disengagement and online moral disengagement are different constructs although they are correlated, suggesting that adolescents may use distinct online setting features in order to disengage in the moral sphere. Some studies found that moral disengagement was related to antisocial 
behaviors such as cyberbullying and cyber-aggression (Gini, Pozzoli, \& Hymel, 2014; Marín-López, Zych, Monks \& Ortega-Ruiz, 2019). Pornari and Wood (2010) studied how cyberspace could create the illusion that actions carried out online are not harmful and consequently, encouraging moral disengagement. This is based on the cyberperpetrator's inability to see the reaction of the cybervictim, and the distance between the cyberperpetrator and cybervictim which would reduce the possibility of being empathetic with the cybervictim. They argued that cyberspace has structural characteristics that could make it easier for people to morally disengage when interacting online which could therefore increase the prevalence rates of cyberbullying. It has also been argued (Bauman, 2010; Perren \& Sticca, 2011) that cyberperpetrators may not be aware of the impact of their negative behavior by not observing the cybervictim's reaction, thus making moral disengagement mechanisms less necessary.

Paciello and colleagues (2020) studied the relationship among traditional moral disengagement, online moral disengagement and cyberbullying. They concluded that traditional moral disengagement and online moral disengagement, in adolescents, were two different but correlated constructs. They also found that online moral disengagement was a key factor when studying antisocial behavior in cyberspace such as cyberbullying. Given the importance of moral disengagement when interacting offline and online, more research is needed in order to discover how moral disengagement and empathy impact antisocial behaviors when applied specifically during an online interpersonal interaction.

\section{The current study}

Details regarding how people empathize or employ moral disengagement mechanisms when involved in cyberbullying still need to be discovered. Moreover, longitudinal research that makes it possible to distinguish predictors and correlates of cyberbullying is urgently needed. Thus, the current study aimed to analyze the relations among cyberbullying, online empathy and moral disengagement through technology cross-sectionally and longitudinally. It was hypothesized (H1) that more online empathy is related to less cyberbullying involvement, and that more moral disengagement through technology is related to more cyberbullying involvement (H2). It was also hypothesized that higher levels of online empathy are related to lower levels of moral disengagement through technology (H3). Finally, it was hypothesized that these associations would be observed cross-sectionally and longitudinally (H4). 


\section{METHODOLOGY}

\section{PARTICIPANTS}

This study was conducted with a convenience sample of 1,033 students between 11 and 17 years old $(\mathrm{M}=13.66, \mathrm{SD}=1.64) ; 48.32 \%$ were girls. They were enrolled in 8 public and private schools in Seville, Cordoba, and Cordoba province (Andalusia, Spain). Participants were distributed among the grades as follows: Primary school, Grade 6: 19.43\%; Secondary school, Grade 1: 23.87\%, Grade 2: 17.39\%, Grade 3: 19.70\%, and Grade 4: $19.61 \%$.

In order to carry out longitudinal analyses, a second data collection wave was carried out after an interval of one year. The wave two sample included 534 (52.17\% of the overall original sample) participants enrolled in the eight schools which participated in Time 1, with ages ranging between 12 and 18 years old $(\mathrm{M}=14.10, \mathrm{SD}=1.33) ; 49.82 \%$ were girls. Participants were distributed among the grades as follows: Secondary, Grade 1: $22.73 \%$, Grade 2: $28.85 \%$, Grade 3: $22.90 \%$, and Grade 4: $25.52 \%$ ). A part of the sample was missing for diverse reasons. Mainly, all the students in Grade 4 of secondary education who participated in Time $1(\mathrm{~N}=212)$ were not contacted again in Time 2 because they finished their secondary education before the second wave of data collection. Among the contacted students, data were missing for several reasons such as the anonymous code used to pair the subjects' questionnaires being illegible or incomplete, students changed school or students absent during the data collection day for different reasons (individual absences, school trips, heat wave in the south of Spain). The attrition rate was $34.17 \%$. Regarding the analysis of the missing data, in general, there were no important differences between the students who participated in both waves and those who dropped out. However, some differences have been detected in the variables Moral Justification $(\mathrm{t}=$ 2.56; $\mathrm{p}=.011)$, Diffusion of Responsibility $(\mathrm{t}=2.07 ; \mathrm{p}=.039)$ and Distortion of Consequences $(\mathrm{t}=2.59 ; \mathrm{p}=0.01)$ with higher scores in students who dropped out. Cohen's $d$ was calculated to check the size of the effects, being small in the three cases (Moral Justification, $\mathrm{d}=.15,95 \% \mathrm{CI}=.00-.28)$, Diffusion of Responsibility $(\mathrm{d}=.15$, $95 \% \mathrm{CI}=.00-.29)$ and Distortion of consequences $(\mathrm{d}=.15,95 \% \mathrm{CI}=.00-.29)$. Given that our study focuses on analyzing relations among variables, it is not expected that these differences have affected the results. 


\section{INSTRUMENTS}

European Cyberbullying Intervention Project Questionnaire (ECIP-Q; Del Rey et al., 2015; Ortega-Ruiz, Del Rey, \& Casas, 2016) is a cyberbullying measure with 22 items organized in two dimensions. It shows excellent reliability with a Cronbach's $\alpha=.97$. There are 11 items for Cybervictimization (e.g., someone has posted embarrassing photographs or videos of me on the Internet) which has good reliability with Cronbach's alpha of .80 in the Spanish validation by Ortega-Ruiz and colleagues (2016); and Cronbach's $\alpha=.94$ in the current study. There are also 11 items for Cyberperpetration (e.g., I have posted embarrassing photographs or videos of someone on the Internet) which has good reliability with Cronbach's alpha of .88 in the Spanish validation by Ortega-Ruiz and colleagues (2016); and Cronbach's $\alpha=.95$ in the current study. Participants were asked to answer the questionnaire referring to "the past school year". Items were answered on a five-point Likert scale ranging from 0 (never) to 4 (more than once a week). The current data adjusted adequately to this two-factor structure according to a confirmatory factor analysis results $\left(\mathrm{SB} \chi^{2}=712.94\right.$; $\mathrm{df}=208 ; \mathrm{NFI}=.97$; NNFI $=$ $.98 ; \mathrm{CFI}=.98 ; \mathrm{RMSEA}=.05,90 \% \mathrm{CI}=.045-.052$ ).

Online Empathy Questionnaire (Marín-López, Zych, Ortega-Ruiz, \& Monks, 2019) is a validated measure to assess the use of empathy while interacting through electronic devices. It is based on the Basic Empathy Scale (Jolliffe \& Farrington, 2006) and it has two dimensions, affective empathy and cognitive empathy with good reliability values in both the validation study and the current study $(\alpha=.82)$. The first subscale has 4 items for Online Cognitive Empathy (e.g., When I interact through a mobile phone or the Internet, I understand the emotions of whom I interact with) and showed good reliability with a Cronbach's $\alpha=.87$ in the current study. The second subscale has 3 items for Online Affective Empathy (e.g., The emotions of people with whom I interact on a mobile phone or the Internet affect me a lot) and showed an acceptable Cronbach's $\alpha=.66$ in the current study. Participants were asked to answer the questionnaire referring to "the past school year". Items were answered on a five-point Likert scale ranging from 0 (never) to 4 (more than once a week). The current data adjusted adequately to this two-factor structure according to a confirmatory factor analysis $\left(\mathrm{SB} \chi^{2}=53.15 ; \mathrm{df}=13 ; \mathrm{NFI}=.98\right.$; NNFI $=.98 ; \mathrm{CFI}=.99 ; \mathrm{RMSEA}=.05,90 \% \mathrm{CI}=.040-.071)$.

Moral Disengagement through Technology Questionnaire (Marín-López et al., 2019) is a validated measure based on the Moral Disengagement scale designed by Bandura, Barbaranelli, Caprara and Pastorelli (1996) but adapted to online interpersonal 
interactions. It is a 16-item questionnaire and items are grouped in four moral disengagement strategies including all the moral disengagement mechanisms (see Bandura et al., 1996). It demonstrated good reliability, with a Cronbach's $\alpha=.95$ in the current study. Moral Justification through Technology has 4 items (e.g., Insulting or mocking someone via mobile phone or the Internet to fight for something important is okay) and showed a good Cronbach's $\alpha=.91$. Diffusion of Responsibility through Technology has 4 items (e.g., If no one has banned it, people are not to blame for mocking someone through mobile phone or the Internet) and showed a good Cronbach's $\alpha=.91$. Distortion of Consequences through Technology has 4 items (e.g., Insults through mobile phone or Internet do not hurt anyone) and showed a good Cronbach's $\alpha=.91$. Attribution of Blame through Technology has 4 items (e.g., If someone makes a ridiculous picture or video of him/herself, it is his/her fault if people spread it by mobile phone or the Internet) and showed a good Cronbach's $\alpha=.86$. Participants were asked to answer the questionnaire referring to "the past school year". Items were answered on a five-point Likert scale ranging from 0 (never) to 4 (more than once a week). The current data adjusted adequately to this four-factor structure according to confirmatory factor analysis results $\left(\mathrm{SB} \chi^{2}=242.14 ; \mathrm{df}=98 ; \mathrm{NFI}=.99 ; \mathrm{NNFI}=.99 ; \mathrm{CFI}=.99 ; \mathrm{RMSEA}=.04,90 \%\right.$ $\mathrm{CI}=.032-.044)$.

All questionnaires used in this work were filled in both at Time 1 and Time 2 .

\section{DESIGN AND PROCEDURE}

This was a longitudinal prospective study conducted through self-report surveys. It was approved by the Ethics Committee of the University of XXXXXX and followed the ethical standards of the Declaration of Helsinki. Headteachers were contacted and asked to collaborate in the study. Parental consent was obtained for each participant. Participants completed the questionnaires during their regular classroom hours in about 30 minutes, under the supervision of the senior researchers, who delivered and collected the questionnaires with no teacher intervention. Before filling in the questionnaires, participants were informed of the voluntary and anonymous character of their participation, the objectives of the current study were explained, and they had the right to withdraw from the study at any time. An anonymous code was used to match questionnaires answered at both waves. 


\section{DATA ANALYSES}

Confirmatory Factor Analyses were carried out using EQS 6.2, in order to check the psychometric properties of the instruments. Several indices were used to examine the model fit. Maximum likelihood method and polychoric correlations (Satorra-Bentler chisquare) were used. Given that chi-square is sensitive to sample size, different indices were used to assess the model fit, including the CMIN/DF, CFI, and RMSEA. Reference values for a good fitting model are CMIN/DF under 3-4; CFI above .95; and RMSEA of .06 or lower (Bentler, 1992; Hu \& Bentler, 1999). Reliability coefficient Cronbach's Alpha was calculated using Factor software. First, bivariate Pearson's correlation coefficients and ANOVA coefficients for T1 (cross-sectional relations) were calculated using SPSS v22. Then, predictors of $\mathrm{T} 1$ were studied in relation to outcomes at $\mathrm{T} 2$. Thus, if a $\mathrm{T} 1$ predictor was only related to the outcome at $\mathrm{T} 1$, it was considered to be cross-sectionally related but if a T1 predictor was related to the outcome one year later (at T2), it was considered to be a predictor of future behavior too.

Participants were classified in the different cyberbullying roles of Cyberperpetrator, Cybervictim, Cyberbully/victim and Uninvolved considering their responses to the ECIP-Q. Scoring 0 to 1 (never or once) on all the items related to Cyberperpetration and Cybervictimization, meant that a participant was considered Uninvolved. Scoring 2 or more (two times a year or more) on any item related to Cyberperpetration and 0 or 1 on all the Cybervictimization items, resulted in a participant being classified as a Cyberperpetrator. Scoring 2 or more on any Cybervictimization item and 0 or 1 on all the Cyberperpetration items, led a participant to be classified as a Cybervictim. Scoring 2 or more on any Cyberperpetration and any Cybervictimization item meant that a participant was considered a Cyberbully/victim.

Levene's homogeneity test was carried out to check the homogeneity of variance. Scores for Online Empathy and Moral Disengagement through Technology were compared with a one-way ANOVA test (in case of homogeneous variance) and with Welch's ANOVA test (a correction when variance is heterogeneous) among different cyberbullying roles. Post-hoc comparisons were carried out, using Bonferroni post-hoc comparisons when the variance was homogeneous and Games-Howell post-hoc comparisons when the variance was heterogeneous. A multinomial logistic regression on cyberbullying roles, in both times 1 and 2 as dependent variables compared to Uninvolved participants, were carried out using SPSS v22, to analyze cross-sectional and longitudinal 
relations among the studied variables in each cyberbullying role. Age, Sex, Online Empathy and Moral Disengagement through Technology at time 1 were included as predictors to test whether these variables where uniquely related (cross-sectionally or longitudinally) to involvement in different cyberbullying roles in both T1 and T2.

\section{RESULTS}

The correlation matrix including Cybervictimization, Cyberperpetration, Online Empathy and Moral Disengagement through Technology is presented in Table 1. It was found that high Cybervictimization was associated to high total score in Online Empathy and to high Moral Disengagement through Technology including its total score and all its subscales. It was also found that high Cyberperpetration was related to high Moral Disengagement through Technology including the total score and all its subscales. High Moral Justification through Technology was related to high Online Empathy including all its subscales. It was also found that high Online Cognitive Empathy was associated to the high total score in Moral Disengagement through Technology. See Table 1 for more details.

\section{Insert table 1}

After carrying out Levene's homogeneity of variances test, Empathy online and Moral disengagement through Technology scores in different cyberbullying roles were compared using a one-way ANOVA (see table 2). Table 2 shows the T1 level of Online Empathy and Moral Disengagement through Technology among cyberbullying roles including Cybervictims, Cyberperpetrators, Cyberbully/victims and Uninvolved in times 1 and 2. No group differences regarding Online Empathy were found among different cyberbullying roles. Regarding Moral Disengagement through Technology, scores were generally higher in children involved in cyberbullying when compared to uninvolved, especially for cyberbully/victims. Considering the longitudinal comparison, scores for Moral Justification through Technology and Attribution of Blame through Technology were higher in cyberbully/victims compared to the uninvolved participants one year later and the total score in Moral Disengagement through Technology was higher in cyberbully/victims than uninvolved one year later. 
Insert table 2

Multinomial logistic regression analysis including predictors such as Sex, Age, Online Empathy and Moral Disengagement through Technology of each cyberbullying role at time 1 and time 2 were carried out (see Table 3 ). Thus, considering these variables at time 1 as predictors of the Cybervictim role, results showed no significant relations for any of the studied variables at any time point (Sex, Age, Online Empathy and Moral Disengagement through Technology; see table 3). Results showed that high Moral Justification through Technology predicted being a Cyberperpetrator cross-sectionally $(\mathrm{OR}=1.15 ; 95 \% \mathrm{CI}=1.03-1.29)$ and also longitudinally $(\mathrm{OR}=1.22 ; 95 \% \mathrm{CI}=1.04-1.42)$, becoming a stronger predictor one year later (see table 3). The results for the Cyberbully/victim role, indicated that two variables were significant, Age and Moral Justification through Technology (see table 3). Being a cyberbully/victim was predicted by older age at the two timepoints, acting as a longitudinal predictor (T1: $\mathrm{OR}=1.19$; 95\% CI=1.01-1.41; T2: OR=1.40; 95\%CI=1.03-1.90). High Moral Justification through Technology was significantly related to involvement as a cyberbully/victim only crosssectionally $(\mathrm{OR}=1.24,95 \% \mathrm{CI}=1.14-1.35)$.

\section{Insert table 3}

\section{DISCUSSION}

Cyberbullying is a serious damaging type of interpersonal violence present in and out of schools all over the world (Zych, Ortega-Ruiz, \& Del Rey, 2015) which can occur at any time, day or night, and is not confined to the school playground (Kowalski, Limber, \& McCord, 2019). Involvement in cyberbullying has worrying consequences such as poorer levels of mental health (Hase, Goldberg, Smith, Stuck, \& Campain, 2015), psychosomatic problems (Beckman, Hagquist, \& Hellström, 2012) and symptoms of depression and suicidal ideation (Bonanno \& Hymel, 2013). Although great advances have been made in cyberbullying research (Zych et al., 2015), there are still gaps in our understanding of the phenomenon that need to be addressed. It is relevant to keep advancing towards the cyberbullying eradication as it is still present and prevalent in our society (Zych et al., 
2016). Thus, it is vital to understand which variables predict cyberbullying cross-sectionally and longitudinally. In this respect, very little is known about the role of online empathy and moral disengagement while interacting through technology in relation to cyberbullying.

The purpose of this study was to analyze the relations among cyberbullying and the online dimensions of two complex constructs; empathy and moral disengagement, and to explore these relationships cross-sectionally and longitudinally. The findings of the current study, both cross-sectional and longitudinal, contribute to a more precise understanding of cyberbullying. The longitudinal approach brings new insights regarding the role of some relatively novel predictors such as online empathy and moral disengagement through technology disentangled from correlates.

Similarly to Lazuras, Barkoukis, Ourda and Tsorbatzoudis (2013), who found that affective empathy was a predictor of cyberbullying expectations, and contrary to what was expected (H1), results indicated that higher involvement in cybervictimization was related to higher levels of online empathy. The role of online empathy in cyberbullying does not seem to be clear, although previous studies (Ang \& Goh, 2010; Steffgen et al., 2011; Zych et al., 2019) showed the tendency to score lower in empathy when children engage in cyberbullying perpetration and higher in empathy when they are cybervictims. Nevertheless, in line with Lazuras and colleagues (2013), the results suggest that the effect of empathy, in its online dimension in the present study in cyberbullying can become nonsignificant when other predictors are considered. As Lazuras and colleagues (2013) proposed, the importance of empathy should not be questioned, although its role should be analyzed in more detail and its interactions with and/or influence on other predictive variables of cyberbullying should be explored.

Lazuras and colleagues (2013) found that moral disengagement was a predictor of cyberbullying expectations, as it was expected (H2) and confirmed in our study, results indicated that higher involvement in cybervictimization was related to higher levels of moral disengagement through technology. In line with previous studies (Lazuras et al., 2013; Pornari \& Wood, 2010; Renati et al., 2012) and in accordance hypothesis 2, higher involvement in cyberperpetration was related to higher levels of moral disengagement through technology. Nevertheless, a higher level of moral disengagement through technology was related to a higher level of online empathy which is a rather unexpected finding, contrary to the hypothesis 3 . It could be that the ability to understand and share other's emotional states or contexts is sometimes related to undesirable personal traits 
related to being manipulative and Machiavellian ways of achieving goals such as callousunemotional traits, low fearfulness or insensitivity to punishment (Fanti, Panayiotou, Lazarou, Michael \& Georgiou, 2016). These characteristics could be interfering with the internalization of moral standards and with the ignorance of the consequences of immoral behaviors (Shulman, Cauffman, Piquero \& Fagan, 2011). Moral justification through technology was found to be a risk factor for cyberperpetration, supporting Renati and colleagues' work (2012). Cyberbully/victims scored higher than both uninvolved and cybervictims in moral disengagement through technology. In accordance with Renati and colleagues (2012) and the current findings, if both cyberperpetrators and cybervictims scored higher in moral disengagement, the cyberbully/victim, a role that is a conjunction of being a cyberperpetrator while being cybervictimized, also scored higher in moral disengagement.

Regarding hypothesis 4, diverse results were cross-sectionally and longitudinally observed. High levels of moral justification through technology was related to more involvement in cyberbullying as a cyberperpetrator, and it was found to be a longitudinal predictor of cyberperpetration becoming stronger one year later $(\mathrm{H} 4)$. Older age was related to being a cyberbully/victim cross-sectionally and one year later. High levels of moral justification through technology was cross-sectionally related to being a cyberbully/victim. Paciello and colleagues (2008) found a relation between being regularly involved in aggressive and deviant behaviors and a tendency to a chronic use of moral disengagement, in a longitudinal study, which could add support to the finding of the present study. These findings seem to underline the important role of moral disengagement through technology regarding the cyberbullying phenomenon, and point out, in line with Paciello and colleagues (2020), that moral disengagement through technology is a different construct from the traditional moral disengagement, being important for the cyberbully/victim role which is usually understudied.

As future research lines, it would be interesting and useful to include moral emotions, "online disinhibition effect" (Suler, 2004) and "deindividuation" (Silke, 2003) in the dynamic of cyberbullying- related interpersonal variables. To get a more complete understanding of moral disengagement mechanisms, more studies are needed to examine the reasons why cyberperpetrators morally disengage, in order to tackle cyberbullying by educating young people from a socio-emotional and positive perspective. It could help to tackle not only cyberbullying but also other online antisocial behaviors such as cyberhate 
or cybercrime, since it has been found that antisocial behaviors form patterns (Nasaescu, Zych, Ortega-Ruiz, Farrington \& Llorent, 2020) and therefore holistic interventions are needed.

This study has some limitations such as the use of self-reports only and the convenience sampling. Future research could benefit also from adding parent-reports, teacher-reports and/or peer-reports regarding involvement in cyberbullying, although it is usually difficult for parents and teachers to identify when a child is involved in cyberbullying. Future research with representative samples and cross-cultural and cross-national studies could shed new light on cyberbullying and its relationship with online empathy and moral disengagement through technology in different contexts. Even with these limitations, the current study has important implications for policy and practice as it described two relatively new phenomena such as empathy online and moral disengagement through technologies in relation to cyberbullying cross-sectionally and longitudinally.

\section{References}

Anderson, C. A., Shibuya, A., Ihori, N., Swing, E. L., Bushman, B. J., Sakamoto, A., ... Saleem, M. (2010). Violent video game effects on aggression, empathy, and prosocial behavior in Eastern and Western countries: A meta-analytic review. Psychological Bulletin, 136, 151173. https://doi.org/10.1037/a0018251

Ang, R. P. \& Goh, D. H. (2010). Cyberbullying among adolescents: The role of affective and cognitive empathy, and gender. Child Psychiatry \& Human Development, 41(4), 387397. https://doi.org/10.1007/s10578-010-0176-3

Bandura, A. (2002). Selective moral disengagement in the exercise of moral agency. Journal of moral education, 31, 101-119. https://doi.org/10.1080/0305724022014322 B

Bandura, A. (1990). Mechanisms of moral disengagement. In W. Reich (Ed.), Origins of Terrorism: psychologies, ideologies, theologies, states of mind (pp. 161-191). Cambridge, UK: Cambridge University Press.

Bandura, A. (2016). Moral disengagement: How people do harm and live with themselves. Worth Publishers 
Bandura, A. (1991). Social cognitive theory of moral thought and action. In W. M. Kurtines \& J. L. Gewirtz (Eds.), Handbook of moral behavior and development (Vol. 1, pp. 45103). Hillsdale, NJ: Erlbaum.

Bandura, A., Barbaranelli, C., Caprara, G. V., \& Pastorelli, C. (1996). Mechanisms of moral disengagement in the exercise of moral agency. Journal of Personality and Social Psychology, 71(2), 364. https://doi.org/10.1037/0022-3514.71.2.364

Bauman, S. (2010). Cyberbullying in a rural intermediate school: An exploratory study. The Journal of Early Adolescence, 30(6), 803-833. https://doi.org/10.1177/0272431609350927

Beckman, L., Hagquist, C., \& Hellström, L. (2012). Does the association with psychosomatic health problems differ between cyberbullying and traditional bullying? Emotional and Behavioural Difficulties, 17, 421-434. https://doi.org/10.1080/13632752.2012.704228

Bentler, P. M. (1992). On the fit of models to covariances and methodology to the Bulletin. Psychological Bulletin, 112(3), 400. https://doi.org/10.1037/0033-2909.112.3.400

Bonanno, R. A. \& Hymel, S. (2013). Cyber bullying and internalizing difficulties: Above and beyond the impact of traditional forms of bullying. Journal of Youth and Adolescence, 42, 685-697. https://doi.org/10.1007/s10964-013-9937-1.

Brewer, G. \& Kerslake, J. (2015). Cyberbullying, self-esteem, empathy and loneliness. Computers in Human Behavior, 48, 255-260. https://doi.org/10.1016/j.chb.2015.01.073

Bussey, K., Fitzpatrick, S., \& Raman, A. (2015). The role of moral disengagement and selfefficacy in cyberbullying. Journal of School Violence, 14(1), 30-46. https://doi.org/10.1080/15388220.2014.954045

Caplan, S. E. \& Turner, J. S. (2007). Bringing theory to research on computer-mediated comforting communication. Computers in Human Behavior,23(2), 985-998. https://doi.org/10.1016/j.chb.2005.08.003

Carrier, L. M., Spradlin, A., Bunce, J. P., \& Rosen, L. D. (2015). Virtual empathy: Positive and negative impacts of going online upon empathy in young adults. Computers in Human Behavior, 52, 39-48. https://doi.org/10.1016/j.chb.2015.05.026 
Casas, J. A., Ortega-Ruiz, R., \& Monks, C. P. (2020) Cyberbullying: A changing phenomenon. In N. Van Zalk \& C. P. Monks (Eds.) Online Peer Engagement in Adolescence. London: Routledge.

Cohen, D. \& Strayer, J. (1996). Empathy in conduct-disordered and comparison youth. Developmental Psychology, 32, 988-998. https://doi.org/10.1037/0012-1649.32.6.988

Del Rey, R., Casas, J. A., Ortega-Ruiz, R., Schultze-Krumbholz, A., Scheithauer, H., Smith, P.,... Plichta, P. (2015). Structural validation and cross-cultural robustness of the European Cyberbullying Intervention Project Questionnaire. Computers in Human Behavior, 50, 141-147. https://doi.org/10.1016/j.chb.2015.03.065

Doane, A. N., Pearson, M. R., \& Kelley, M. L. (2014). Predictors of cyberbullying perpetration among college students: An application of the theory of reasoned action. Computers in Human Behavior, 36, 154-162. https://doi.org/10.1016/j.chb.2014.03.051

Fanti, K. A., Panayiotou, G., Lazarou, C., Michael, R., \& Georgiou, G. (2016). The better of two evils? Evidence that children exhibiting continuous conduct problems high or low on callous-unemotional traits score on opposite directions on physiological and behavioral measures of fear. Development and Psychopathology,28(1), 185-198. https://doi.org/10.1017/S0954579415000371

Gámez-Guadix, M., Borrajo, E., \& Almendros, C. (2016). Risky online behaviors among adolescents: Longitudinal relations among problematic Internet use, cyberbullying perpetration, and meeting strangers online. Journal of Behavioral Addictions, 5(1), 100107. https://doi.org/10.1556/2006.5.2016.013

Garaigordobil, M. \& Martínez-Valderrey, V. (2015). Effects of Cyberprogram 2.0 on" face-toface" bullying, cyberbullying, and empathy. Psicothema, 27(1), 45-51. https://doi.org/10.7334/psicothema2014.78

Gini, G., Pozzoli, T., \& Hymel, S. (2014). Moral disengagement among children and youth: A meta-analytic review of links to aggressive behavior. Aggressive Behavior, 40(1), 56-68. https://doi.org/10.1002/ab.21502

Hase, C. N., Goldberg, S. B., Smith, D., Stuck, A., \& Campain, J. (2015). Impacts of traditional bullying and cyberbullying on the mental health of middle school and high school students. Psychology in the Schools, 52, 607-617. https://doi.org/10.1002/pits.21841 
Hu, L. T. \& Bentler, P. M. (1999). Cutoff criteria for fit indexes in covariance structure analysis: Conventional criteria versus new alternatives. Structural Equation Modeling: A Multidisciplinary Journal, 6(1), 1-55. https://doi.org/10.1080/10705519909540118

Jolliffe, D., \& Farrington, D. P. (2006). Development and validation of the Basic Empathy Scale. Journal of Adolescence, 29, 589-611. https://doi.org/10.1016/j.adolescence.2005.08.010

Jolliffe, D. \& Farrington, D. P. (2004). Empathy and offending: A systematic review and metaanalysis. Aggression $\quad$ and $\quad$ Violent $\quad$ Behavior, 9(5), 441-476. https://doi.org/10.1016/j.avb.2003.03.001

Juvonen, J. \& Gross, E. F. (2008). Extending the school grounds? Bullying experiences in cyberspace. Journal of School Health, 78(9), 496-505. https://doi.org/10.1111/j.17461561.2008.00335.x

Kokkinos, C. M., Antoniadou, N., \& Markos, A. (2014). Cyber-bullying: An investigation of the psychological profile of university student participants. Journal of Applied Developmental Psychology,35(3), 204-214. https://doi.org/10.1016/j.appdev.2014.04.001

Kowalski, R. M., Giumetti, G. W., Schroeder, A. N., \& Lattanner, M. R. (2014). Bullying in the digital age: A critical review and meta-analysis of cyberbullying research among youth. Psychological Bulletin, 140(4), 1073. https://doi.org/10.1037/a0035618

Kowalski, R. M. \& Limber, S. P. (2007). Electronic bullying among middle school students. Journal of Adolescent Health,41(6), S22-S30. https://doi.org/10.1016/j.jadohealth.2007.08.017

Kowalski, R. M., Limber, S. P., \& McCord, A. (2019). A developmental approach to cyberbullying: Prevalence and protective factors. Aggression and Violent Behavior, 45, 20-32. https://doi.org/10.1016/j.avb.2018.02.009

Lazuras, L., Barkoukis, V., Ourda, D., \& Tsorbatzoudis, H. (2013). A process model of cyberbullying in adolescence. Computers in Human Behavior, 29(3), 881-887. https://doi.org/10.1016/j.chb.2012.12.015

Marín-López, I., Zych, I., Monks, C. P., \& Ortega-Ruiz, R. (2019). Empathy, Morality and Social and Emotional Competencies in Interpersonal Interactions Online. In M. Coetzee (Ed.), Thriving in Digital Workspaces (pp. 217-233). Cham, Switzerland: Springer. 
Marín-López, I., Zych, I., Ortega-Ruiz, R., \& Monks, C. (2019) Validación y propiedades psicométricas del Cuestionario de Empatía Online y el Cuestionario de Desconexión Moral a través de las Tecnologías. In A.F. Chica Pérez \& J. Mérida García (Eds.), Creando Redes Doctorales Vol. VII “Investiga y Comunica” (pp. 525-528). Córdoba, Spain: UCOPress. Menesini, E., Nocentini, A., Palladino, B. E., Frisén, A., Berne, S., Ortega-Ruiz, R., ... \& Naruskov, K. (2012). Cyberbullying definition among adolescents: A comparison across six European countries. Cyberpsychology, Behavior, and Social Networking, 15(9), 455463. https://doi.org/10.1089/cyber.2012.0040

Modecki, K. L., Minchin, J., Harbaugh, A. G., Guerra, N. G., \& Runions, K. C. (2014). Bullying prevalence across contexts: A meta-analysis measuring cyber and traditional bullying. Journal of Adolescent Health, 55(5), 602-611. https://doi.org/10.1016/j.jadohealth.2014.06.007

Nasaescu, E., Zych, I., Ortega-Ruiz, R., Farrington, D.P., \& Llorent, V.J. (2020). Longitudinal Patterns of Antisocial Behaviors in Early Adolescence: A Latent Class and Latent Transition Analysis. The European Journal of Psychology Applied to Legal Context, Ahead of print. https://doi.org/10.5093/ejpalc2020a10

Nocentini, A., Calmaestra, J., Schultze-Krumbholz, A., Scheithauer, H., Ortega, R., \& Menesini, E. (2010). Cyberbullying: Labels, behaviours and definition in three European countries. Journal of Psychologists and Counsellors in Schools, 20(2), 129-142. https://doi.org/10.1375/ajgc.20.2.129

Ortega-Ruiz, R., Del Rey, R., \& Casas, J. A. (2016). Evaluar el bullying y el cyberbullying validación española del EBIP-Q y del ECIP-Q. Psicología Educativa, 22, 71-79. https://doi.org/10.1016/j.pse.2016.01.004

Pabian, S., Vandebosch, H., Poels, K., Van Cleemput, K., \& Bastiaensens, S. (2016). Exposure to cyberbullying as a bystander: An investigation of desensitization effects among early adolescents. Computers in Human Behavior, 62, 480-487. https://doi.org/10.1016/j.chb.2016.04.022

Paciello, M., Fida, R., Tramontano, C., Lupinetti, C., \& Caprara, G. V. (2008). Stability and change of moral disengagement and its impact on aggression and violence in late adolescence. Child Development, 79(5), 1288-1309. https://doi.org/10.1111/j.14678624.2008.01189.x 
Paciello, M., Tramontano, C., Nocentini, A., Fida, R., \& Menesini, E. (2020). The role of traditional and online moral disengagement on cyberbullying: Do externalising problems make any difference? Computers in Human Behavior, 103, 190-198. https://doi.org/10.1016/j.chb.2019.09.024

Patchin, J. W. \& Hinduja, S. (2006). Bullies move beyond the schoolyard: A preliminary look at cyberbullying. Youth Violence and Juvenile Justice, 4(2), 148-169. https://doi.org/10.1177/1541204006286288

Perren, S. \& Gutzwiller-Helfenfinger, E. (2012). Cyberbullying and traditional bullying in adolescence: Differential roles of moral disengagement, moral emotions, and moral values. European Journal of Developmental Psychology,9(2), 195-209. https://doi.org/10.1080/17405629.2011.643168

Perren, S. \& Sticca, F. (2011, March). Bullying and morality: are there differences between traditional bullies and cyberbullies. In Society for Research in child development biennial meeting, Montreal, $Q C$.

Pettalia, J. L., Levin, E., \& Dickinson, J. (2013). Cyberbullying: Eliciting harm without consequence. Computers in Human Behavior, 29(6), 2758-2765. https://doi.org/10.1016/j.chb.2013.07.020

Pornari, C. D. \& Wood, J. (2010). Peer and cyber aggression in secondary school students: The role of moral disengagement, hostile attribution bias, and outcome expectancies. Aggressive Behavior, 36, 81-94. https://doi.org/10.1002/ab.20336

Renati, R., Berrone, C., \& Zanetti, M. A. (2012). Morally disengaged and unempathic: Do cyberbullies fit these definitions? An exploratory study. Cyberpsychology, Behavior, and Social Networking, 15(8), 391-398. https://doi.org/10.1089/cyber.2012.0046

Retuerto, A. (2002). Desarrollo del razonamiento moral, razonamiento moral prosocial y empatía en la adolescencia y juventud (Ph.D. Dissertation). Spain: University of Valencia.

Robson, C. \& Witenberg, R. T. (2013). The influence of moral disengagement, morally based self-esteem, age, and gender on traditional bullying and cyberbullying. Journal of School Violence, 12(2), 211-231. https://doi.org/10.1080/15388220.2012.762921

Runions, K. C. \& Bak, M. (2015). Online moral disengagement, cyberbullying, and cyberaggression. Cyberpsychology, Behavior, and Social Networking, 18, 400-405. https://doi.org/10.1089/cyber.2014.0670 
Schultze-Krumbholz, A. \& Scheithauer, H. (2009). Social-behavioral correlates of cyberbullying in a German student sample. Zeitschrift für psychologie/Journal of Psychology, 217(4), 224-226. https://doi.org/10.1027/0044-3409.217.4.224

Shulman, E. P., Cauffman, E., Piquero, A. R., \& Fagan, J. (2011). Moral disengagement among serious juvenile offenders: A longitudinal study of the relations between morally disengaged attitudes and offending. Developmental Psychology, 47(6), 1619. https://doi.org/10.1037/a0025404

Silke, A. (2003). Deindividuation, anonymity, and violence: Findings from Northern Ireland. The $\begin{array}{lllll}\text { Journal } & \text { of } & \text { Social } & \text { Psychology, } & \text { 149, }\end{array}$ https://doi.org/10.1080/00224540309598458

Slonje, R. \& Smith, P. K. (2008). Cyberbullying: Another main type of bullying? Scandinavian Journal of Psychology, 49, 147-154. https://doi.org/10.1111/j.1467-9450.2007.00611.x

Smith, P. K., Mahdavi, J., Carvalho, M., Fisher, S., Russell, S., \& Tippett, N. (2008). Cyberbullying: Its nature and impact in secondary school pupils. Journal of Child Psychology and Psychiatry, 49(4), 376-385. https://doi.org/10.1111/j.14697610.2007.01846.x

Sorrentino, A., Baldry, A. C., Farrington, D. P., \& Blaya, C. (2019). Epidemiology of Cyberbullying across Europe: Differences between Countries and Genders. Educational Sciences: Theory and Practice, 19(2), 74-91. https://doi.org/10.12738/estp.2019.2.005

Steffgen, G., König, A., Pfetsch, J., \& Melzer, A. (2011). Are cyberbullies less empathic? Adolescents' cyberbullying behavior and empathic responsiveness. Cyberpsychology, Behavior, and Social Networking, 14(11), 643-648. https://doi.org//10.1089/cyber.2010.0445

Sugarman, D. B. \& Willoughby, T. (2013). Technology and violence: Conceptual issues raised by the rapidly changing social environment. Psychology of Violence,3(1), 1. https://doi.org/10.1037/a0031010

Suler, J. (2004). The online disinhibition effect. Cyberpsychology \& Behavior, 7, 321-326. https://doi.org/10.1037/a0031010

Tokunaga, R. S. (2010). Following you home from school: A critical review and synthesis of research on cyberbullying victimization. Computers in Human Behavior, 26(3), 277-287. https://doi.org/10.1016/j.chb.2009.11.014 
Van Zalk, M. H. W., Van Zalk, N., Kerr, M., \& Stattin, H. (2014). Influences between online exclusive, conjoint and offline-exclusive friendship networks: The moderating role of shyness. European Journal of Personality, 28, 134-146. https://doi.org/10.1002/per.1895

Vieno, A., Gini, G., \& Santinello, M. (2011). Different forms of bullying and their association to smoking and drinking behavior in Italian adolescents. Journal of School Health, 81(7), 393-399. https://doi.org/10.1111/j.1746-1561.2011.00607.x

Wachs, S. (2012). Moral disengagement and emotional and social difficulties in bullying and cyberbullying: Differences by participant role. Emotional and Behavioral Difficulties, 17(3-4), 347-360. https://doi.org/10.1080/13632752.2012.704318

Wolak, J., Mitchell, K., \& Finkelshor, D. (2008). Unwanted and wanted exposure to online pornography in a national sample of youth Internet users. Pediatrics, 119, 247-257. https://doi.org/10.1542/peds.2006-1891

Yadava, A., Sharma, N. R., \& Gandhi, A. (2001). Aggression and moral disengagement. Journal of Personality and Clinical Studies, 17(2), 95-99.

Zych, I., Baldry, A. C., Farrington, D. P., \& Llorent, V. J. (2019). Are children involved in cyberbullying low on empathy? A systematic review and meta-analysis of research on empathy versus different cyberbullying roles. Aggression and Violent Behavior, 45, 83-97. https://doi.org/10.1016/j.avb.2018.03.004

Zych, I., Gómez-Ortiz, O., Touceda, L. F., Nasaescu, E., \& Llorent, V. J. (2019). Parental Moral Disengagement Induction as a Predictor of Bullying and Cyberbullying: Mediation by Children's Moral Disengagement, Moral Emotions, and Validation of a Questionnaire. Child Indicators Research, 1-19. https://doi.org/10.1007/s12187-01909670-2

Zych, I., \& Llorent, V. J. (2019). Affective empathy and moral disengagement related to late adolescent bullying perpetration. Ethics \& Behavior, 29, 547-556. https://doi.org/10.1080/10508422.2018.1521282

Zych, I., Ortega-Ruiz, R., \& Del Rey, R. (2015). Systematic review of theoretical studies on bullying and cyberbullying: Facts, knowledge, prevention, and intervention. Aggression and Violent Behavior, 23, 1-21. https://doi.org/10.1016/j.avb.2015.10.001

Zych, I., Ortega-Ruiz, R., \& Marín-López, I. (2016). Cyberbullying: a systematic review of research, its prevalence and assessment issues in Spanish studies. Psicología Educativa, 22(1), 5-18. https://doi.org/10.1016/j.pse.2016.03.002 


\section{Table 1}

Correlations among Cybervictimization, Cyberperpetration, Online Empathy and Moral Disengagement through Technology

\begin{tabular}{|c|c|c|c|c|c|c|c|c|c|c|}
\hline & 1 & 2 & 3 & 4 & 5 & 6 & 7 & 8 & 9 & 10 \\
\hline 1.Cybervictimization (T1) & 1 & & & & & & & & & \\
\hline 2.Cyberperpetration (T1) & .57 & 1 & & & & & & & & \\
\hline 3.Online Cognitive Empathy (T1) & .06 & .06 & 1 & & & & & & & \\
\hline 4.Online Affective Empathy (T1) & .04 & .04 & $.34 * *$ & 1 & & & & & & \\
\hline 5.Online Empathy total (T1) & $.07^{*}$ & .06 & $.88^{* *}$. & $.75^{* *}$ & 1 & & & & & \\
\hline 6. Moral Justification through Technology (T1) & $.21^{* *}$ & $.35^{* *}$ & $.13^{* *}$ & $.06^{*}$ & $.12^{* *}$ & 1 & & & & \\
\hline 7.Difusion of Responsibility through Technology (T1) & $.18^{* *}$ & $.33^{* *}$ & .01 & .02 & .02 & $.56^{* *}$ & * 1 & & & \\
\hline 8.Distortion of Consequences through Technology (T1) & $.18^{* *}$ & $.27^{* *}$ & -.01 & -.04 & -.03 & $.40 * *$ & $* .56^{* *}$ & $=1$ & & \\
\hline 9.Attribution of Blame through Technology (T1) & $.15^{* *}$ & $.16^{* *}$ & .05 & -.02 & .03 & $.44 * *$ & $* .47 * *$ & $.47 * *$ & 1 & \\
\hline 10.Moral Disengagement through Technology total (T1) & $.23^{* *}$. & $.35^{* *}$ & $.07^{*}$ & .02 & .06 & $.78 * *$ & $* .81 * *$ & $.73^{* *}$ & $.80 * *$ & 1 \\
\hline
\end{tabular}

Note. Pearson $\mathrm{r}$ correlations; $* \mathrm{p}<.05 ; * * \mathrm{p}<.01$. 


\section{Table 2}

One way ANOVAs comparisons among cyberbullying roles: Cybervictims, Cyberperpetrators, Cyberbully/victims and Uninvolved

\begin{tabular}{|c|c|c|c|c|c|c|c|c|c|c|c|c|c|c|}
\hline $\begin{array}{l}\text { Online Cognitive Empathy } \\
\text { (T1) }\end{array}$ & $\begin{array}{l}13.20 \\
(4.10)\end{array}$ & $\begin{array}{l}12.98 \\
(4.23)\end{array}$ & $\begin{array}{l}12.97 \\
(3.84)\end{array}$ & $\begin{array}{l}12.88 \\
(4.32)\end{array}$ & $\begin{array}{l}12.95 \\
(4.45)\end{array}$ & $\begin{array}{l}13.94 \\
(2.39)\end{array}$ & $\begin{array}{l}13.73 \\
(3.83)\end{array}$ & $\begin{array}{l}14.18 \\
(3.54)\end{array}$ & $.635^{\mathrm{a}}$ & 1.17 & $3,108.52$ & 3,518 & - & - \\
\hline Online Empathy total (T1) & $\begin{array}{l}21.09 \\
(5.82)\end{array}$ & $\begin{array}{l}20.78 \\
(5.91)\end{array}$ & $\begin{array}{l}21.12 \\
(5.46)\end{array}$ & $\begin{array}{l}20.91 \\
(5.99)\end{array}$ & $\begin{array}{l}21.00 \\
(5.97)\end{array}$ & $\begin{array}{l}22.89 \\
(3.27)\end{array}$ & $\begin{array}{l}21.56 \\
(5.37)\end{array}$ & $\begin{array}{l}22.55 \\
(5.11)\end{array}$ & $.176^{\mathrm{a}}$ & $3.03 * \mathrm{a}$ & $3,108.32$ & 3,512 & - & - \\
\hline $\begin{array}{l}\text { Moral Justification through } \\
\text { Technology (T1) }\end{array}$ & $\begin{array}{l}6.08 \\
(2.97)\end{array}$ & $\begin{array}{l}6.00 \\
(2.94)\end{array}$ & $\begin{array}{l}6.49 \\
(2.63)\end{array}$ & $\begin{array}{l}6.23 \\
(2.99)\end{array}$ & $\begin{array}{l}8.37 \\
(4.65)\end{array}$ & $\begin{array}{l}8.53 \\
(4.80)\end{array}$ & $\begin{array}{l}9.62 \\
(4.45)\end{array}$ & $\begin{array}{l}8.21 \\
(4.21)\end{array}$ & $32.70^{* *}$ & $4.30^{* * a}$ & $3,322.43$ & 3,520 & $\begin{array}{l}\text { CP-U; } \\
\text { CBV-U; } \\
\text { CBV-CV }\end{array}$ & $\begin{array}{l}\text { CBV- } \\
\mathrm{U}\end{array}$ \\
\hline $\begin{array}{lr}\text { Distortion } & \text { of } \\
\text { Consequences } & \text { through }\end{array}$ & $\begin{array}{l}5.07 \\
(2.15)\end{array}$ & $\begin{array}{l}5.01 \\
(2.24)\end{array}$ & $\begin{array}{l}5.25 \\
(2.37)\end{array}$ & $\begin{array}{l}5.06 \\
(1.82)\end{array}$ & $\begin{array}{l}5.19 \\
(2.08)\end{array}$ & $\begin{array}{l}5.39 \\
(2.50)\end{array}$ & $\begin{array}{l}6.39 \\
(2.97)\end{array}$ & $\begin{array}{l}6.28 \\
(3.22)\end{array}$ & $7,92 * *$ & $3.23^{*}$ & $3,39.8$ & 3,519 & $\begin{array}{l}\text { CBV-U; } \\
\text { CBV-CV }\end{array}$ & - \\
\hline Technology (T1) & & & & & & & & & & & & & & \\
\hline $\begin{array}{l}\text { Attribution of Blame } \\
\text { through Technology (T1) }\end{array}$ & $\begin{array}{l}7.43 \\
(3.60)\end{array}$ & $\begin{array}{l}7.48 \\
(3.72)\end{array}$ & $\begin{array}{l}8.26 \\
(4.08)\end{array}$ & $\begin{array}{l}7.96 \\
(3.54)\end{array}$ & $\begin{array}{l}8.89 \\
(4.55)\end{array}$ & $\begin{array}{l}7.56 \\
(3.22)\end{array}$ & $\begin{array}{l}8.56 \\
(3.71)\end{array}$ & $\begin{array}{l}9.50 \\
(4.16)\end{array}$ & $3.93 * a$ & $1.66^{\mathrm{a}}$ & $3,103.84$ & 3,518 & - & $\begin{array}{l}\text { CBV- } \\
\mathrm{U}\end{array}$ \\
\hline
\end{tabular}




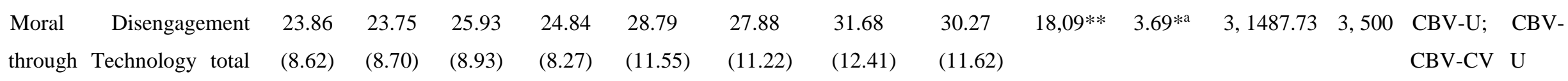

(T1)

CP: cyberperpetrator; CBV: cyberbully/victim; U: uninvolved; CV: cybervictim; ${ }^{a}$ Welch's ANOVA; $* * p<.01 ; * \mathrm{p}<.05$.

Uninvolved T1 n=814, T2 n=429; Cybervictims T1 n=104, T2 n=52; Cyberperpetrators T1 n=36, T2 n=19; Cyberbully/victims T1 n=79, T2 n=34.

Table 3

Multinomial logistic regression for cyberbullying roles in time 1 and time 2 with predictors variables at time 1

\begin{tabular}{|c|c|c|c|c|c|c|c|c|c|c|c|c|c|c|c|c|c|c|}
\hline & \multicolumn{6}{|c|}{ Cybervictims } & \multicolumn{6}{|c|}{ Cyberperpetrators } & \multicolumn{6}{|c|}{ Cyberbully/victim } \\
\hline & \multicolumn{3}{|c|}{$\mathrm{T} 1$} & \multicolumn{3}{|c|}{$\mathrm{T} 2$} & \multicolumn{3}{|c|}{$\mathrm{T} 1$} & \multicolumn{3}{|c|}{$\mathrm{T} 2$} & \multicolumn{3}{|c|}{$\mathrm{T} 1$} & \multicolumn{3}{|c|}{$\mathrm{T} 2$} \\
\hline & OR & \multicolumn{2}{|c|}{$95 \% \mathrm{CI}$} & \multirow{2}{*}{\begin{tabular}{r|} 
OR \\
1.19
\end{tabular}} & \multicolumn{2}{|c|}{$95 \% \mathrm{CI}$} & \multirow{2}{*}{$\begin{array}{r}\text { OR } \\
1.12\end{array}$} & \multicolumn{2}{|c|}{$95 \% \mathrm{CI}$} & \multirow{2}{*}{\begin{tabular}{r|} 
OR \\
1.21
\end{tabular}} & \multicolumn{2}{|c|}{$95 \% \mathrm{CI}$} & \multirow{2}{*}{$\begin{array}{l}\text { OR } \\
.85\end{array}$} & \multicolumn{2}{|c|}{$95 \% \mathrm{CI}$} & \multirow{2}{*}{$\begin{array}{r}\text { OR } \\
1.17\end{array}$} & \multicolumn{2}{|c|}{$95 \% \mathrm{CI}$} \\
\hline Sex (T1) & .77 & .49 & 1.21 & & .62 & 2.28 & & .52 & 2.39 & & .41 & 3.57 & & .48 & 1.51 & & .51 & 2.65 \\
\hline Age (T1) & 1.08 & .95 & 1.23 & .99 & .78 & 1.26 & 1.21 & .98 & 1.51 & 1.38 & .91 & 2.10 & 1.19 & 1.01 & 1.41 & 1.40 & 1.03 & 1.90 \\
\hline $\begin{array}{l}\text { Online Cognitive Empathy } \\
\text { (T1) }\end{array}$ & .97 & .91 & 1.02 & .97 & .90 & 1.05 & .94 & .86 & 1.04 & .99 & .85 & 1.14 & 1.04 & .96 & 1.12 & 1.00 & .90 & 1.11 \\
\hline $\begin{array}{l}\text { Online Affective Empathy } \\
\text { (T1) }\end{array}$ & 1.03 & .94 & 1.11 & 1.04 & .93 & 1.18 & 1.03 & .90 & 1.18 & 1.12 & .92 & 1.36 & .94 & .84 & 1.04 & 1.13 & .97 & 1.30 \\
\hline $\begin{array}{l}\text { Moral Justification through } \\
\text { Technology (T1) }\end{array}$ & 1.05 & .96 & 1.14 & 1.01 & .89 & 1.15 & 1.15 & 1.03 & 1.29 & 1.22 & 1.04 & 1.42 & 1.24 & 1.14 & 1.35 & 1.07 & .94 & 1.22 \\
\hline $\begin{array}{l}\text { Diffusion of Responsibility } \\
\text { through Technology (T1) }\end{array}$ & .99 & .89 & 1.10 & .99 & .84 & 1.16 & 1.10 & .92 & 1.15 & 1.14 & .93 & 1.41 & 1.08 & .96 & 1.21 & 1.05 & .89 & 1.24 \\
\hline
\end{tabular}




\begin{tabular}{|c|c|c|c|c|c|c|c|c|c|c|c|c|c|c|c|c|c|c|}
\hline $\begin{array}{l}\text { Distortion of } \\
\text { Consequences through }\end{array}$ & 1.01 & .89 & 1.14 & 1.02 & .84 & 1.25 & .89 & .73 & 1.08 & .83 & .60 & 1.15 & 1.06 & .93 & 1.22 & 1.00 & .82 & 1.22 \\
\hline \multicolumn{19}{|l|}{ Technology (T1) } \\
\hline $\begin{array}{l}\text { Attribution of Blame } \\
\text { through Technology (T1) }\end{array}$ & 1.06 & .99 & 1.13 & 1.02 & .92 & 1.12 & 1.03 & .92 & 1.15 & .91 & .76 & 1.09 & .93 & .84 & 1.02 & 1.07 & .96 & 1.20 \\
\hline \multirow{2}{*}{ Nagelkerke $\mathrm{R}^{2}$} & \multicolumn{18}{|c|}{$\mathrm{T} 1=.108$} \\
\hline & \multicolumn{18}{|c|}{$\mathrm{T} 2=.089$} \\
\hline
\end{tabular}

The reference comparison category was Uninvolved. 